\title{
Multiple layers of control govern expression of the Escherichia coli ibpAB heat-shock operon
}

Correspondence

Franz Narberhaus

franz.narberhaus@rub.de

Received 16 July 2010

Revised 15 September 2010

Accepted 17 September 2010

\author{
Lena C. Gaubig, Torsten Waldminghaust and Franz Narberhaus \\ Microbial Biology, Ruhr University Bochum, Germany
}

\section{INTRODUCTION}

Bacteria are continuously exposed to changes in environmental conditions. To respond to stress conditions in a timely fashion, they have developed numerous protective strategies that are tightly regulated. Global stress responses are primarily regulated at the level of transcription initiation (Campbell et al., 2008). The induction of stress genes in many bacteria is orchestrated by alternative sigma factors, subunits of the RNA polymerase that direct the holoenzyme to specific promoter sequences. In addition to the housekeeping sigma factor $\sigma^{70}$, the Escherichia coli genome encodes six alternative sigma factors. The most prominent examples are $\sigma^{\mathrm{S}}$ (RpoS), responsible for induction of the general stress response, and $\sigma^{32}(\mathrm{RpoH})$, responsible for initiating heat-shock gene expression (Gross et al., 1998; Guisbert et al., 2008; Hengge-Aronis, 2002).

mRNA degradation and maturation also play important roles in the regulation of gene expression. The inherent stability of an mRNA molecule determines how long it is available as template for translation (Rauhut \& Klug, 1999). The half-life of many mRNAs varies with environmental changes; this is consistent with mRNA stability playing a role in the control of differential gene expression (Newbury et al., 1987).

tPresent address: Department of Cell Biology, Institute for Cancer Research, The Norwegian Radium Hospital, Rikshospitalet, University of Oslo, 0310 Oslo, Norway.

Abbreviations: RACE, rapid amplification of CDNA ends; ROSE, repression of heat-shock gene expression; SD, Shine-Dalgarno; UTR, untranslated region; WT, wild-type.
Regulatory RNAs have recently been recognized as important post-transcriptional gene control elements, often being involved in the coordination of stress responses (Narberhaus \& Vogel, 2009; Waters \& Storz, 2009). Small regulatory RNAs and riboswitches, functioning as trans- and cis-acting regulators, respectively, influence gene expression using various strategies, in most cases depending on RNA-RNA interactions. Riboswitches are structured RNA elements in the $5^{\prime}$ untranslated region (5' UTR) of certain transcripts. Conformational changes upon the binding of a cellular metabolite alter gene expression, which can be controlled at the level of transcription elongation, translation initiation or RNA processing (Winkler \& Breaker, 2005). Likewise, RNA thermometers are structured mRNA regions in the $5^{\prime}$ UTR of temperature-controlled bacterial genes (Narberhaus et al., 2006). They supervise translation initiation by folding into a structure that blocks the Shine-Dalgarno (SD) sequence at low temperatures. A temperature upshift induces melting of the structure, giving access to the ribosome and permitting translation of heat-shock or virulence genes (Narberhaus, 2010).

Numerous cellular processes, including mRNA translation and protein folding, are sensitive to temperature up- and downshifts (Klinkert \& Narberhaus, 2009; Schumann, 2009). Therefore, bacteria precisely monitor changes in their ambient temperature and react accordingly with heat-shock or cold-shock responses. The E. coli heat-shock response is well characterized (Guisbert et al., 2008). A combination of transcriptional and post-transcriptional mechanisms culminate in the synthesis of $\sigma^{32}$ under heat-stress conditions. The sigma factor initiates transcription of heat-shock genes, most of which encode molecular chaperones or proteases. 
The ibpAB operon belongs to the $\sigma^{32}$ regulon. The open reading frames are separated by $111 \mathrm{bp}$ and are the most dramatically induced heat-shock genes in E. coli (Richmond et al., 1999). The encoded small heat-shock proteins IbpA and $\mathrm{IbpB}$ (inclusion body-associated protein A and B) have been found associated with recombinant proteins in inclusion bodies (Allen et al., 1992). They also recognize endogenous E. coli proteins that aggregate in response to heat shock (Laskowska et al., 1996). IbpA and IbpB proteins share $57.5 \%$ sequence identity and exhibit chaperone activity under in vitro conditions (Kitagawa et al., 2000, 2002). IbpB was shown to stabilize stress-denatured proteins for subsequent refolding by a multichaperone network (Veinger et al., 1998). IbpA cooperates with IbpB in this process (Matuszewska et al., 2005). Regulation of the $i b p A B$ operon is complex and not yet fully understood. As well as the transcriptional control of $i b p A B$, translational control of $i b p A$ by an RNA thermometer in its upstream region has also been reported (Waldminghaus et al., 2009). In this study, we closely examined the regulation of the $i b p A B$ operon and discovered additional layers of control.

\section{METHODS}

Bacterial strains, plasmids, oligonucleotides and growth conditions. All strains, plasmids and oligonucleotides used in this study are listed in Table 1. E. coli cells were grown at 30 or $37{ }^{\circ} \mathrm{C}$ in LuriaBertani (LB) medium supplemented with ampicillin (Amp, $200 \mu \mathrm{g}$ $\mathrm{ml}^{-1}$ ) and/or kanamycin (Km, $50 \mu \mathrm{g} \mathrm{ml}^{-1}$ ), as needed.

Plasmid construction. Recombinant DNA work was performed according to standard protocols (Sambrook et al., 1989). Site-directed mutagenesis to generate pBO668 was performed according to the instruction manual of the QuikChange mutagenesis kit (Stratagene). The correct nucleotide sequence of all plasmids was confirmed by automated sequencing. Detailed information on plasmid construction and characteristics is shown in Table 1.

Construction of an ibpAB mutation in E. coli C600. E. coli C600 $\triangle i b p A B$ was constructed by $\mathrm{P} 1$ transduction according to standard protocols (Sambrook et al., 1989). E. coli JGT14 served as donor (Shearstone \& Baneyx, 1999).

RNA isolation and Northern blot analysis. Cells were grown at $30{ }^{\circ} \mathrm{C}$ to exponential phase and an aliquot of the culture was heatshocked at $42{ }^{\circ} \mathrm{C}$ for $1 \mathrm{~min}$. To measure RNA stability, $250 \mu \mathrm{g}$ rifampicin $\mathrm{ml}^{-1}$ was added $1 \mathrm{~min}$ after heat shock. Samples were then taken at 0, 3, 6, 10 and $15 \mathrm{~min}$ after the addition of rifampicin. Isolation of total RNA and Northern blotting were performed as described previously (Waldminghaus et al., 2005). Digoxigenin-labelled RNA probes were produced according to the instruction manual (Roche).

5' Rapid amplification of cDNA ends (RACE). 5' RACE experiments were conducted as described previously (Willkomm et al., 2005) with minor modifications. DNase treatment was performed with $2 \mathrm{U}$ DNase I (Promega) and $40 \mathrm{U}$ RiboLock (Fermentas). Reverse transcription was carried out with SuperScript III (Invitrogen), according to the manufacturer's instructions. After PCR amplification with the adaptor primer and a gene-specific primer (primers ECIbpBPErv for the $5^{\prime}$ end of the monocistronic $i b p B$ transcript and 5RACE_ibpB_k for the $5^{\prime}$ end of short $i b p B$ fragments; Table 1), prominent bands were excised from $2 \%$ agarose gels, eluted and blunt-end cloned into pUC18 restricted with SmaI. The inserts of several plasmids from each experiment were sequenced.

In vitro transcription of RNA. RNA for toeprint analyses and structure probing was synthesized in vitro by run-off transcription with T7 RNA polymerase, from linearized plasmids or PCR-generated DNA templates (Table 1).

Primer extension inhibition (toeprinting). Toeprinting experiments were carried out using $30 \mathrm{~S}$ ribosomal subunits, target mRNA and tRNAfMet basically according to Hartz et al. (1988). The $5^{\prime}-{ }^{32} \mathrm{P}-$ labelled $i b p A$ - and $i b p B$-specific oligonucleotides ibpACDSrv and T7ibpBrv (Table 1), complementary to nucleotides +66 to +43 and +69 to +50 of the $i p b A$ and $i b p B$ coding sequences, respectively, were used as primers for cDNA synthesis. A 0.08 pmol aliquot of $i b p A B$ or $i b p B$ mRNA annealed to the appropriate oligonucleotide was incubated for 10 min at 30 or $42{ }^{\circ} \mathrm{C}$ together with 16 pmol uncharged tRNAfMet (Sigma-Aldrich). $30 \mathrm{~S}$ subunits $(6 \mathrm{pmol})$ or Watanabe buffer $(60 \mathrm{mM}$ HEPES/KOH; $10.5 \mathrm{mM} \mathrm{Mg}(\mathrm{COO})_{2} ; 690 \mathrm{mM} \mathrm{NH}_{4} \mathrm{COO} ; 12 \mathrm{mM} \beta$ mercaptoethanol; $10 \mathrm{mM}$ spermidine; $0.25 \mathrm{mM}$ spermine; negative control) were added, and incubated for another $10 \mathrm{~min}$ at 30 or $42{ }^{\circ} \mathrm{C}$. Then $2 \mu \mathrm{l}$ MMLV-Mix (VD $+\mathrm{Mg}^{2+}$ buffer, BSA, dNTPs and MMLV reverse transcriptase; USB) was added. cDNA synthesis was performed at the respective temperature. Reactions were stopped after $10 \mathrm{~min}$ by adding formamide loading dye and aliquots were separated on a denaturing $8 \%$ polyacrylamide gel.

In vitro RNA structure probing. RNAs were $5^{\prime}$ end-labelled as described previously (Brantl \& Wagner, 1994). Digestions were carried out with RNase T1 (Ambion). In a total volume of $4 \mu \mathrm{l}$, RNA corresponding to 30000 c.p.m. was mixed with $1 \mu l 5 \times$ TMN buffer (100 mM Tris/acetate; $10 \mathrm{mM} \mathrm{MgCl}$; $500 \mathrm{mM} \mathrm{NaCl} ; \mathrm{pH} 7.5$ ) and $0.4 \mu \mathrm{g}$ tRNA. One microlitre of RNase T1 was added after 5 min of incubation at the respective temperature. After an additional incubation of $5 \mathrm{~min}$, the reaction was stopped by adding $5 \mu \mathrm{l}$ formamide loading dye. Samples were denatured at $95{ }^{\circ} \mathrm{C}$ for $5 \mathrm{~min}$ and an aliquot of each digest was loaded on an $8 \%$ polyacrylamide gel. Alkaline ladders were generated as described by Brantl \& Wagner (1994).

$\boldsymbol{\beta}$-Galactosidase assay. $\beta$-Galactosidase activity of $E$. coli strains carrying bgaB fusions was measured as described by Miller (1972) with some modifications. For cell disruption, $0.5 \mu \mathrm{g}$ lysozyme $\mu \mathrm{l}^{-1}$ and $25 \mu \mathrm{l} 4 \times \mathrm{Z}$-buffer (with $14 \mu \mathrm{l} \beta$-mercaptoethanol $\mathrm{ml}^{-1}$ ) were added to $400 \mu \mathrm{l}$ of cell suspension and incubated at $55{ }^{\circ} \mathrm{C}$ for $15 \mathrm{~min}$. The enzymic reaction was started at $55^{\circ} \mathrm{C}$ by adding ONPG $\left(2 \mathrm{mg} \mathrm{ml}^{-1}\right.$ in $1 \times \mathrm{Z}$-buffer with $2.7 \mu \mathrm{l} \beta$-mercaptoethanol $\mathrm{ml}^{-1}$ ). Standard deviations (SD) were calculated from at least three independent experiments.

Computer-based methods. Sequences for computer-based analysis were retrieved from GenBank (http://www.ncbi.nlm.nih.gov/ Genbank/). RNA secondary structure was predicted by using the mfold server (http://frontend.bioinfo.rpi.edu/applications/mfold/cgibin/rna-form1.cgi) running version 3.2 (Zuker, 2003). The AIDA image analyser software v. 4.03 was used for toeprint and structureprobing gel analysis.

\section{RESULTS}

\section{Four transcript species derive from the $i b p A B$ operon}

To analyse transcriptional and post-transcriptional events involved in $i b p A B$ regulation, we synthesized RNA probes against the individual genes (Fig. 1a). The $i b p A$ probe reacted with both $i b p A$ and $i b p B$ whereas the $i b p B$ probe 
Table 1. Strains, plasmids and oligonuleotides used in this study

\begin{tabular}{|c|c|c|}
\hline Strain, plasmid or oligonucleotide & Relevant characteristic(s) or sequence ${ }^{\star}$ & $\begin{array}{l}\text { Source, reference or } \\
\text { application }\end{array}$ \\
\hline \multicolumn{3}{|l|}{ E. coli strains } \\
\hline C600 & $\mathrm{F}^{-}$tonA21 thi-1 thr-1 leuB6 lacY1 glnV44 rfbC1 fhuA1 $\lambda^{-}$ & Laboratory collection \\
\hline JGT14 & BL21(DE3) $\Delta i b p 1:: k a n$ & Shearstone \& Baneyx (1999) \\
\hline C600 $\triangle i b p A B$ & C600 $\triangle i b p A B$ & This study \\
\hline N3431 & $\mathrm{Rne}^{-}$ & Goldblum \& Apririon (1981) \\
\hline N3433 & $\mathrm{Rne}^{+}$ & Goldblum \& Apririon (1981) \\
\hline BL321 & $\mathrm{Rnc}^{-}$ & Studier $(1975)$ \\
\hline BL322 & $\mathrm{Rnc}^{+}$ & Studier (1975) \\
\hline \multicolumn{3}{|l|}{ Plasmids } \\
\hline pK18 & Cloning vector, $\mathrm{Km}^{\mathrm{R}}$ & Pridmore (1987) \\
\hline pUC18 & Cloning vector, $\mathrm{Amp}^{\mathrm{R}}$ & Norrander et al. (1983) \\
\hline pBAD-bgaB (pBO415) & Translational $b g a B$ fusion vector ( $b g a B$ : heat-stable $\beta$-galactosidase), $\mathrm{Amp}^{\mathrm{R}}$ & Waldminghaus et al. (2007) \\
\hline pUC-ibpA (pBO403) & E. coli ibpA fragment in $\mathrm{pK} 18$ & Waldminghaus et al. (2009) \\
\hline pUC-ibpB (pBO1059) & E. coli $i b p B$ fragment in $\mathrm{pUC18}$ & This study \\
\hline $\mathrm{pK}-i b p A B(\mathrm{pBO} 1001)$ & E. coli $i b p A B$ fragment in $\mathrm{pK} 18$ & This study \\
\hline pK-ibpABstop (pBO668) & E. coli $i b p A B$ stop fragment in $\mathrm{pK} 18$ & This study \\
\hline pUC-run-off $i b p A B$-toe & E. coli $i b p A B$ toeprint fragment in pUC18 & This study \\
\hline pBAD-ibpA-bgaB (pBO417) & E. coli $i b p A$ fusion in $\mathrm{pBAD}-b g a B$; NheI-EcoRI fragment of $\mathrm{pBO} 403$ & Waldminghaus et al. (2009) \\
\hline $\mathrm{pBAD}-i b p B-b g a B(\mathrm{pBO} 1060)$ & E. coli $i b p B$ fusion in $\mathrm{pBAD}-\operatorname{bgaB}$; NheI-EcoRI fragment of $\mathrm{pBO} 1059$ & This study \\
\hline pBAD-ibpAB-bgaB (pBO629) & E. coli $i b p A B$ fusion in $\mathrm{pBAD}-$ bgaB; NheI-EcoRI fragment of $\mathrm{pBO} 1001$ & This study \\
\hline pBAD-ibpABstop-bgaB (pBO669) & E. coli ibpABstop fusion in $\mathrm{pBAD}-$ bgaB; NheI-EcoRI fragment of $\mathrm{pBO} 668$ & This study \\
\hline \multicolumn{3}{|c|}{ Oligonucleotides } \\
\hline ibpAproberv & TAATACGACTCACTATAgttgatttcgatacggcgcg & $i b p A$ RNA probe \\
\hline ibpAprobefw & caggataatctgctggtggtg & $i b p A$ RNA probe \\
\hline ibpBproberv & TAATACGACTCACTATAgctatttaacgcgggacgtt & $i b p B$ RNA probe \\
\hline ibpBprobefw & acgcgcctgagcgtaaaagg & $i b p B$ RNA probe \\
\hline Adaptor primer & ctcgttagggattgctgac & 5' RACE \\
\hline ECIbpBPErv & gatccattgacgcatcagtgg & 5' RACE \\
\hline 5RACE_ibpB_k & ttagctatttaacgcgggacgt & 5' RACE \\
\hline T7ibpAfw & GAAATTAATACGACTCACTATAGGgccgatgaggacgcgcctga & $\begin{array}{l}\text { Run-off vector in vitro } \\
\text { transcription }\end{array}$ \\
\hline T7ibpBrv & cagtgcgttggccagtttgt & $\begin{array}{l}\text { Run-off vector in vitro } \\
\text { transcription }\end{array}$ \\
\hline ibpB_SP2_fw & GAAATTAATACGACTCACTATAGGGcatctccatgctcgccgtca & Structure probing $i b p B$ \\
\hline ibpB_SP_rv & tacgcatagtcatttctccttct & Structure probing $i b p B$ \\
\hline ibpACDSrv & gtggttaaacaaacggtcaaatcc & Toeprinting $i b p A$ \\
\hline ibpB_5UTR_lang & gctagcattccctaaggccgcctg & Cloning of pBO1059 \\
\hline ibpA1 & tctagctagccgatgaggacgcgcc & $\begin{array}{l}\text { Cloning of pBO } 403 \\
\text { (Waldminghaus et al., 2009) }\end{array}$ \\
\hline IbpA2 & ctagaattcacgcataatcaatagctcctg & Cloning of pBO403, 1001 \\
\hline IbpB2neu & ccggaattcacgcatagtcatttctccttctaa & Cloning of pBO1059, 1001 \\
\hline ibpAstopfw & gatttatccccgctttaaccgttctgctattg & Cloning of pBO668 \\
\hline ibpAstoprv & atccaatagcagaacggttaaagcggggataa & Cloning of pBO668 \\
\hline
\end{tabular}

${ }^{\star}$ T7 promoter in capital letters.

was highly specific to the $i b p B$ transcript (data not shown). Several transcripts of the $i b p A B$ operon were detected by Northern blot analysis (Fig. 1b, c). Due to the $\sigma^{32}$ dependency of the operon, previously described by Allen et al. (1992), the $i b p A B$ transcripts only appeared after heat shock from 30 to $42{ }^{\circ} \mathrm{C}$ and were not detectable in an $r p o H$ mutant (data not shown). Only 2 min after heat shock at $42{ }^{\circ} \mathrm{C}$, the bicistronic transcript was readily detectable by the $i b p A$ (Fig. 1b) and $i b p B$ (Fig. 1c) probes. The massive induction was transient, reached a maximum within a few minutes and declined to almost pre-shock levels after another 5-10 minutes. The concomitant appearance of a band between 500 and $600 \mathrm{nt}$ suggested that the bicistronic message was processed into monocistronic $i b p A$ and $i b p B$ transcripts. Much shorter fragments of approx. $120 \mathrm{nt}$ were detected between 8 and $15 \mathrm{~min}$ after heatshock with the 
(a)

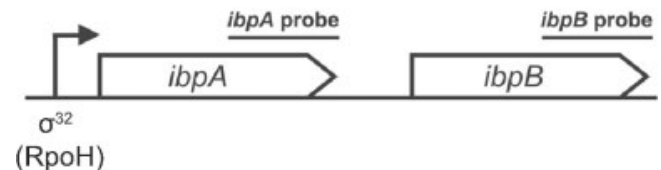

(b)
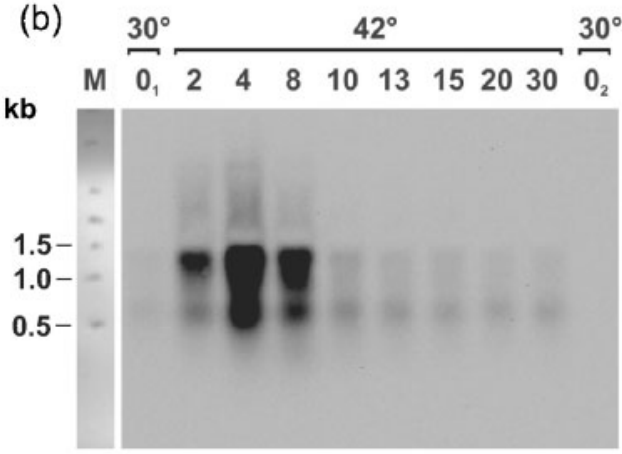

(c)

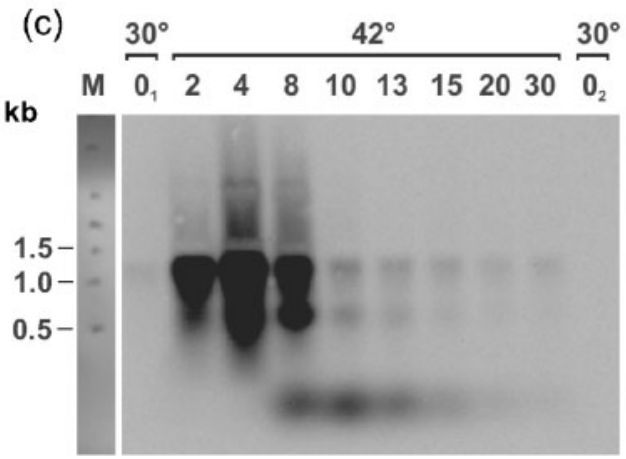

Fig. 1. Multiple RNA species derive from the $E$. coli ibp $A B$ operon. (a) Schematic representation of the E. coli ibpAB operon. Transcription is known to be initiated from a $\sigma^{32}$-dependent promoter (Allen et al., 1992). (b, c) Northern blot analysis of RNA isolated from heat-shocked $E$. coli $\mathrm{C} 600$ cells at the time points indicated and detected using $i b p A$ (b) and $i b p B$ (c) RNA probes. The $O_{1}$ sample was taken before half of the culture was heat shocked. The $\mathrm{O}_{2}$ sample was taken after $30 \mathrm{~min}$ from the culture kept at $30{ }^{\circ} \mathrm{C}$. M, RiboRuler high-range molecular marker (Fermentas).

$i b p B$ RNA probe only (Fig. 1c), suggesting that further processing of the $i b p B$ transcript occurred.

\section{5 '-end determination}

The transcription start site upstream of $i b p A$ has been reported previously (Chuang et al., 1993; Nonaka et al., 2006). To determine the $5^{\prime}$ ends of the monocistronic and the short $i b p B$ transcripts we used 5' RACE analysis. Total RNA was isolated from at least two independent cultures harvested after heat shock from $30{ }^{\circ} \mathrm{C}$ to $42{ }^{\circ} \mathrm{C}$ for $8 \mathrm{~min}$. cDNA was produced by reverse transcription using appropriate oligonucleotides for the $i b p B$ coding region. Six clones revealed a uniform $5^{\prime}$ end of $i b p B$ starting at the second adenine of the ibpA stop codon (Fig. 2a). Hence, the monocistronic $i b p A$ transcript has a size of $509 \mathrm{nt}$, whereas the monocistronic $i b p B$ transcript consists of $584 \mathrm{nt}$. The $5^{\prime}$ end of the short $i b p B$ fragment was less well defined (Fig. 2b); eight clones contained seven different $5^{\prime}$ ends, all between 134 and $94 \mathrm{nt}$ from the presumed $3^{\prime}$ end upstream of a typical factor-independent transcription terminator. To validate the $5^{\prime}$ RACE data, total RNA of heat-shocked E. coli C600 cells was separated on a $10 \%$ polyacrylamide gel and $i b p A B$ fragments were detected with $i b p A$ and $i b p B$ probes (Fig. 2c). As expected, the monocistronic $i b p A$ transcript migrated faster than the $i b p B$ transcript. Various short $i b p B$ fragments are consistent with the 5' RACE results.

\section{RNases involved in ibpAB processing}

To reveal the identity of the RNase(s) responsible for the processing of the $i b p A B$ transcript, we measured the stability of the bicistronic mRNA in a temperaturesensitive RNase $\mathrm{E}$ mutant and an RNase III-negative background. RNase E is essential in E. coli. A shift from 30 to $42{ }^{\circ} \mathrm{C}$ induced transcription of the $i b p A B$ operon and inactivated RNase E in the mutant strain. Decay of the bicistronic transcript after addition of rifampicin in the presence of RNase E and its stability in the absence of the RNase showed that degradation of the $i b p A B$ transcript depends on RNase E (Fig. 3a). Furthermore, RNase E is responsible for the processing of the bicistronic $i b p A B$ RNA, as the monocistronic $i b p B$ transcript and the short $i b p B$ products were detectable in the wild type (WT), whereas they did not appear in the RNase E mutant strain. Note that the monocistronic transcript in the RNase E mutant at time point zero was generated before the temperature-sensitive enzyme was inactivated. If at all, RNase III contributes only marginally to the processing and degradation of the $i b p A B$ transcript because it had comparable half-lives in the wild-type and the RNase III mutant (Fig. 3b).

\section{Heat-stimulated ribosome binding to the $i b p B$ transcript in vitro}

A potential secondary repression of heat-shock gene expression (ROSE)-like RNA structure in the 5' UTR of $i b p B$ suggested that translation might be controlled by an RNA thermometer as is the case for $i b p A$ (Waldminghaus et al., 2009). The putative $i b p B$ thermometer consists of four hairpins in the intergenic region between $i b p A$ and $i b p B$ (see Fig. 5a). The SD sequence is located in hairpin IV and is imperfectly paired with the anti-SD sequence, which exhibits the conserved U(U/C)GCU motif typical of ROSElike elements (Waldminghaus et al., 2005). To evaluate whether the $5^{\prime}$ UTR of $i b p B$ is able to control ribosome access, we tested the temperature-dependent binding of the $30 \mathrm{~S}$ ribosomal subunits to the SD sequence in vitro by toeprinting experiments (Fig. 4). Two in vitro-synthesized RNAs were used (Fig. 4a). They contained either the 
(a)

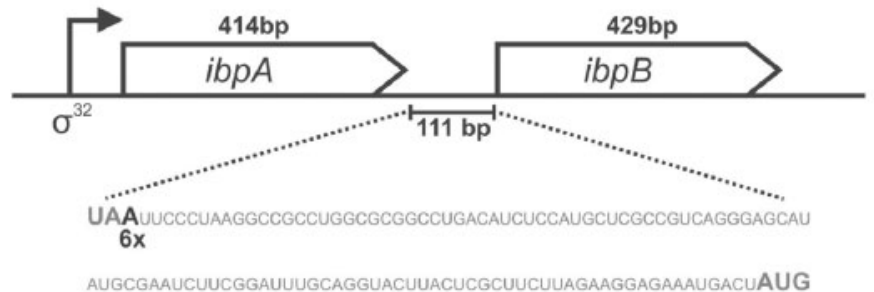

(b)

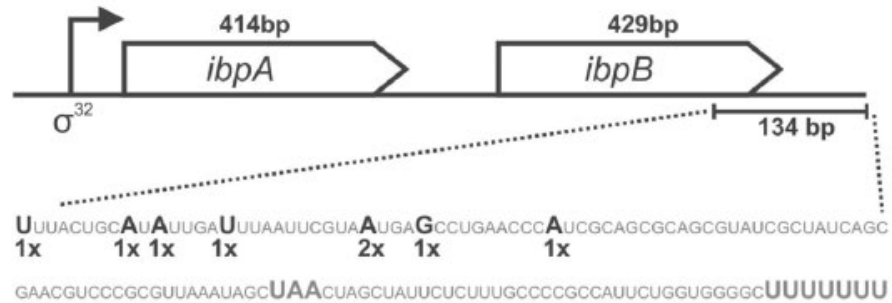

(c)

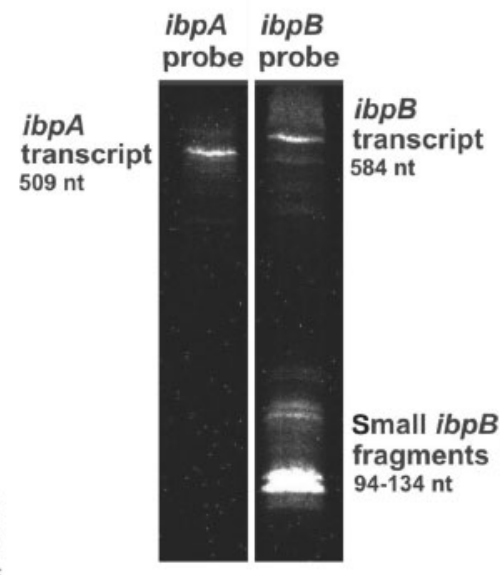

Fig. 2. Determination of the $5^{\prime}$ ends of $i b p B$ transcripts determined by $5^{\prime}$ RACE. The positions of the $5^{\prime}$ ends of the monocistronic $i b p B$ transcript (a) and of short $i b p B$ fragments (b) are indicated below a schematic presentation of the $i b p A B$ operon. UAA and AUG in (a) represent the stop codon of $i b p A$ and the start codon of $i b p B$, respectively. UAA and UUUUUUU in (b) depict the stop codon of $i b p B$ and the predicted $3^{\prime}$ end of the transcript, respectively. (c) Northern blot analysis with RNA isolated from $E$. coli $\mathrm{C} 600$ cells heat-shocked for $8 \mathrm{~min}$. The RNA was separated on a $10 \%$ polyacrylamide gel and ibpAB fragments were detected with the indicated probes.

bicistronic $i b p A B$ region ranging from the $i b p A 5^{\prime}$ UTR to $69 \mathrm{nt}$ into the coding region of $i b p B$ or a shorter fragment containing only the $i b p B 5^{\prime}$ UTR up to $69 \mathrm{nt}$ into the coding region of $i b p B$. Temperature-dependent binding of the $30 \mathrm{~S}$ ribosomes to the $i b p A \mathrm{SD}$ sequence has already been demonstrated by using a short fragment containing only the ibpA 5' UTR (Waldminghaus et al., 2009). Inefficient binding of the $30 \mathrm{~S}$ ribosome to the $i b p A \mathrm{SD}$ sequence at $30{ }^{\circ} \mathrm{C}$ and enhanced formation of the RNAribosome complex at $42{ }^{\circ} \mathrm{C}$ was also observed with the bicistronic $i b p A B$ fragment (Fig. 4b). Binding of the ribosome to the $i b p B$ leader region was equally temperature-sensitive. The absence of a prominent toeprint signal at $30{ }^{\circ} \mathrm{C}$ despite the presence of $30 \mathrm{~S}$ ribosomes suggests that access of the ribosome to the $i b p B \mathrm{SD}$ sequence is blocked by the predicted RNA thermometer structure in (a)
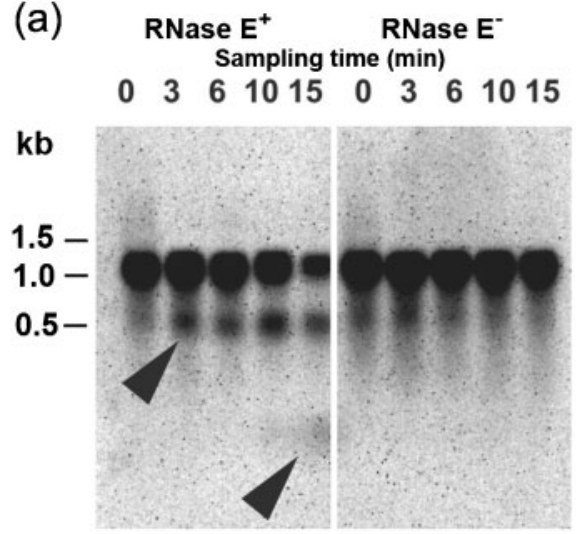

(b)
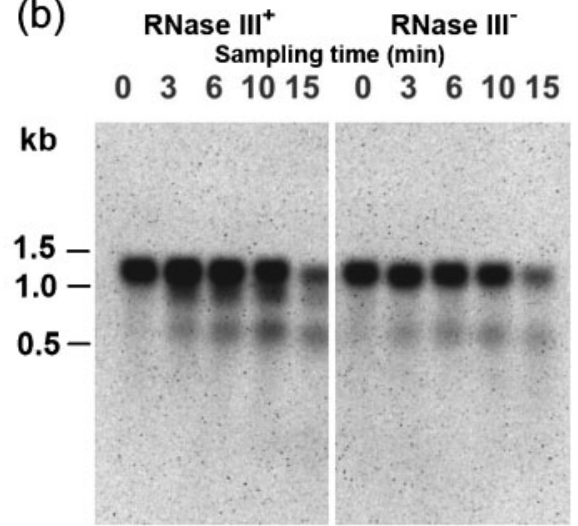

Fig. 3. Processing of $i b p A B$ in RNase-deficient E. coli strains. An E. coli RNase E (a) and an E. coli RNase III (b) mutant strain and their isogenic wild-type strains were grown at $30{ }^{\circ} \mathrm{C}$ to exponential phase and heat-shocked at $42{ }^{\circ} \mathrm{C}$ for 1 min prior to the addition of rifampicin $\left(250 \mu \mathrm{g} \mathrm{ml}^{-1}\right)$. Samples were taken at $0,3,6,10$ and 15 min after the addition of rifampicin. Transcripts were detected using the ibpB RNA probe. Arrowheads in (a) point at RNA fragments appearing after rifampicin addition that are absent in the heat-inactivated mutant strain. 
(a)

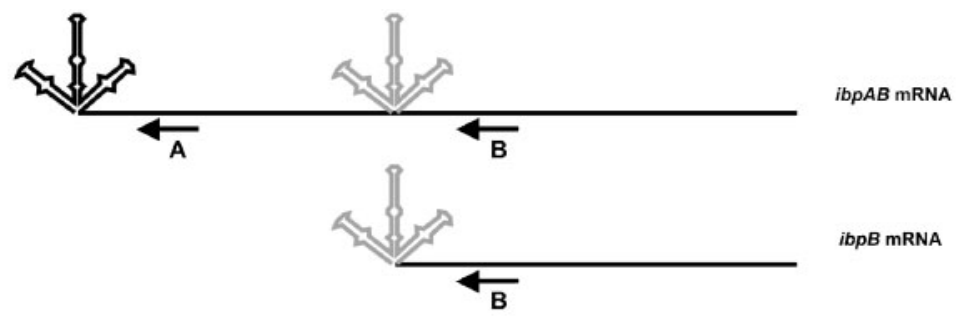

(b)

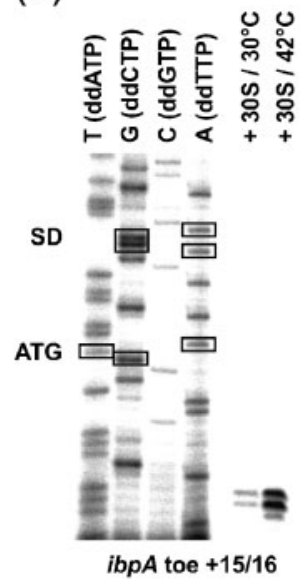

(c)

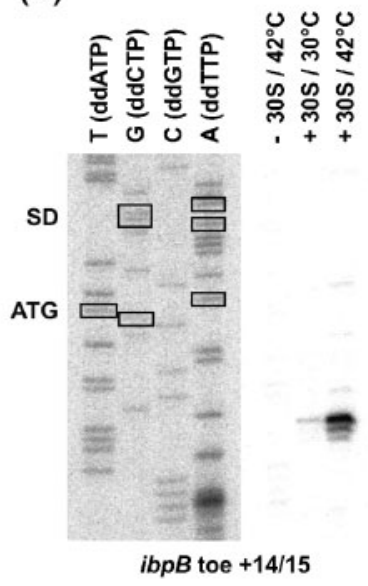

(d)

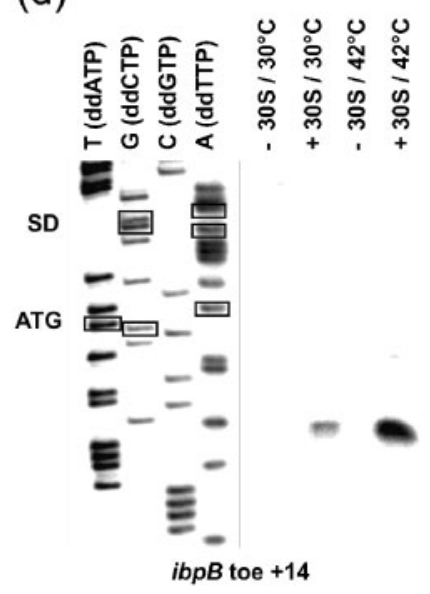

Fig. 4. Temperature-dependent binding of the $30 S$ ribosome to the $5^{\prime}$ UTR of ibpB in vitro. (a) Schematic representation of in vitro-synthesized RNAs and oligonucleotides used for toeprint analyses. (b-d) Toeprinting experiments demonstrating temperature-dependent binding of the $30 S$ ribosomal subunit to the $5^{\prime}$ UTR of $i b p A(b)$ and $i b p B$ (c, d), using the long and short RNA, respectively. Reaction components and conditions are shown above the gels. The corresponding DNA sequencing ladder was generated with the same end-labelled oligonucleotide as used in the toeprinting experiment. Ribosome-binding site (SD), translational start site (ATG) and the toeprinting signals are indicated.

both the long and the short transcript (Fig. 4c and d, respectively). Prematurely terminated reverse transcripts, at $42{ }^{\circ} \mathrm{C}$ and at the typical toeprint position around $15 \mathrm{nt}$ downstream from the AUG start codon, showed that melting of the structured RNA under heat-shock conditions permits translation initiation of $i b p B$ in vitro.

\section{Structural features of the $i b p B 5^{\prime}$ UTR}

To gain structural insights into the putative $i b p B$ thermometer and two $i b p B 5^{\prime}$ UTR variants, structure-probing experiments were carried out with RNase T1 (cleaves $3^{\prime}$ of single-stranded guanines) over a temperature range from 20 to $50{ }^{\circ} \mathrm{C}$ (Fig. 5). To reduce complexity, constructs analogous to the previously studied $i b p A$ thermometer, containing the predicted hairpins II, III and IV of the $i b p B 5^{\prime}$ UTR, were chosen (Fig. $5 \mathrm{a}$ ). The overall cleavage pattern of the $i b p B$ WT UTR supports the predicted structure (Fig. 5b). Cleavage at positions G50, G51 and G52 at low temperatures suggests that the top loop is wider as predicted. The structure of hairpin IV was temperature-responsive. G101, G102 and G104 were barely cleaved at low temperatures but showed increased accessibility to RNase $\mathrm{T} 1$ at temperatures above $40{ }^{\circ} \mathrm{C}$, suggesting liberation of the SD sequence according to the melting model. Probing of the C91A and
$\Delta$ G90 variants (Fig. $5 c, d$ ) provided structural evidence for their derepressed ('Derep') and repressed ('Rep') phenotypes, respectively, in reporter-gene assays (data not shown). In both RNAs, hairpins II and III behaved like the corresponding hairpins of the WT RNA. Hairpin IV of the 'Derep' RNA was more sensitive to RNase T1 cleavage compared to that of the WT (Fig. 5c); prominent cleavage of the guanines in the $\mathrm{SD}$ region already occurred at low temperatures. In the 'Rep' RNA, the SD sequence did not become accessible in the physiological temperature range (Fig. 5d).

\section{IbpA-mediated regulation of $i b p B$ expression}

To further analyse the putative RNA thermometer of the $i b p B 5^{\prime}$ UTR we constructed translational $i b p B$ and $i b p A B$ reporter-gene fusions (Fig. 6a) by using our previously described $b g a B$-reporter system taking advantage of the thermostable $\beta$-galactosidase $\mathrm{BgaB}$ from Bacillus stearothermophilus (Waldminghaus et al., 2007). At $30{ }^{\circ} \mathrm{C}$, expression of the $i b p B$ fusion measured in E. coli C600 was about $110 \mathrm{MU}$ and increased only slightly to $160 \mathrm{MU}$ at $42{ }^{\circ} \mathrm{C}$ (Fig. 6b). Expression of the ibpaB fusion was comparable, whereas the ibpA fusion was heat-inducible, as reported previously (Waldminghaus et al., 2009). Hence, in 
(a)

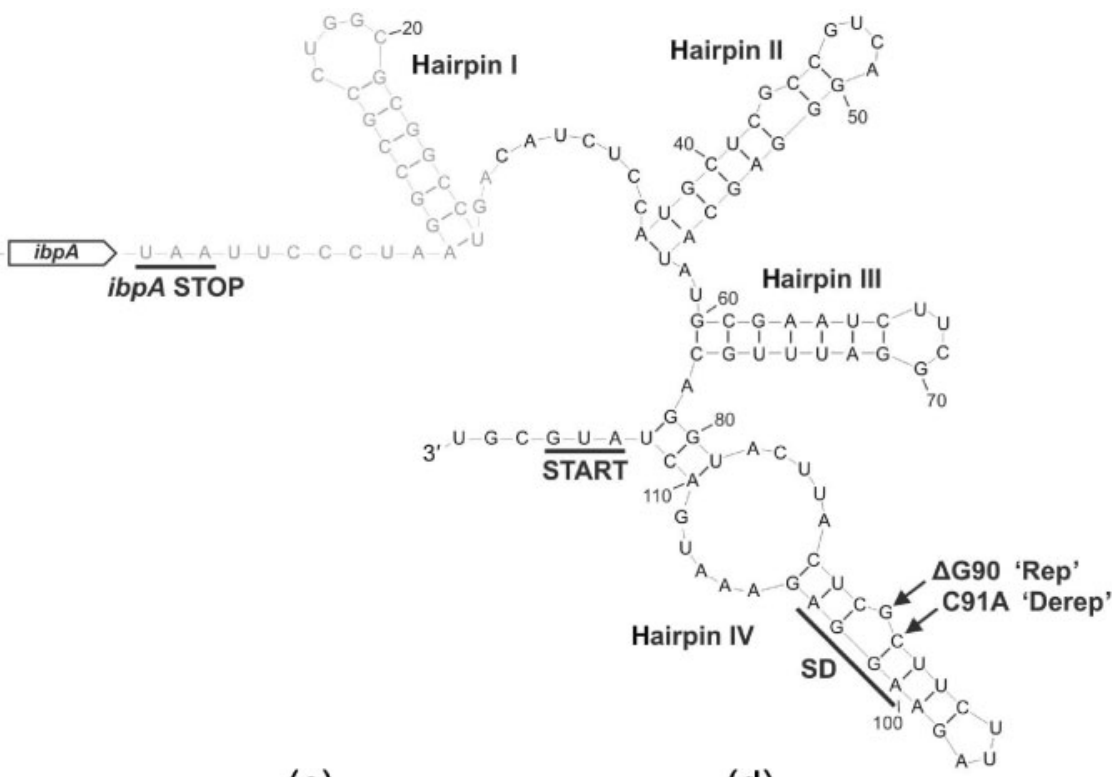

(b)

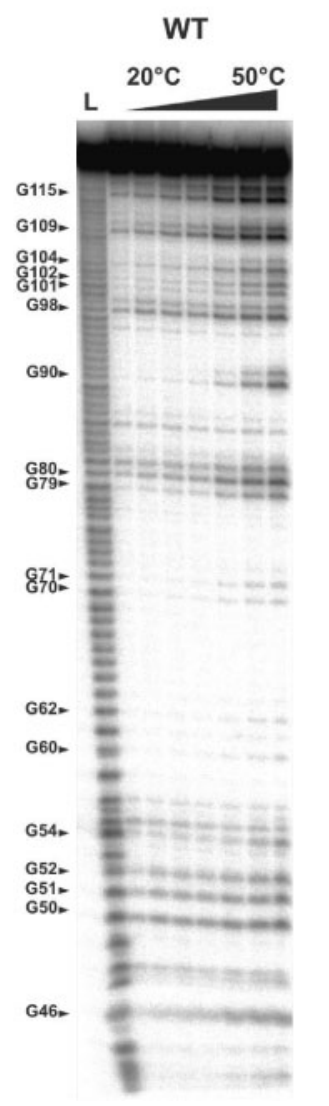

(c)

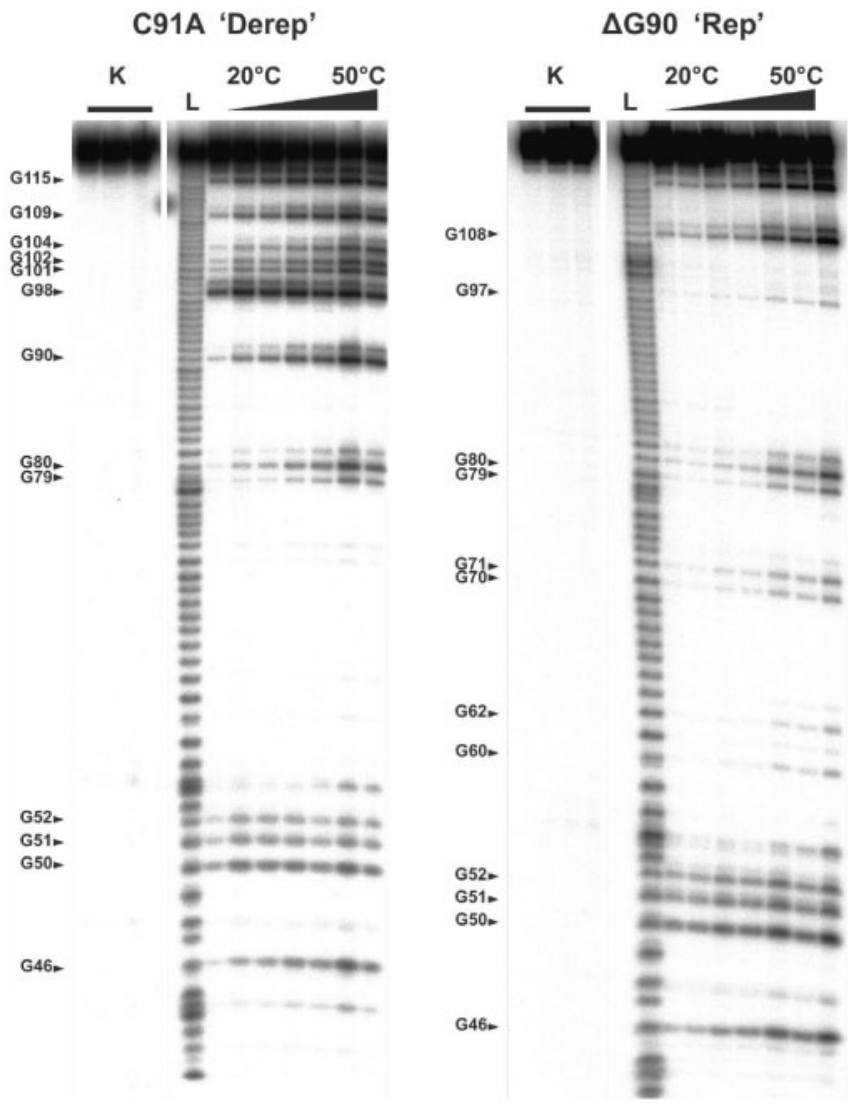

Fig. 5. Structure probing of the $i b p B 5^{\prime}$ UTR. (a) Secondary structure prediction of the $i b p B 5^{\prime}$ UTR made with the mfold program (Zuker, 2003). Nucleotide numbers were arbitrarily chosen starting from the second A of the UAA stop codon of $i b p A$. The sequence shown in black represents the in vitro-synthesized RNA used for structure probing. The SD sequence and AUG start codon of $i b p B$ are indicated as well as single-point mutations of repressed ('Rep') and derepressed ('Derep') variants. (bd) Structure probing of the $i b p B$ WT $5^{\prime}$ UTR (b), the predicted derepressed (c) and the predicted repressed (d) variants. L, alkaline ladder; $\mathrm{K}$, water-treated control RNA. 
(a)

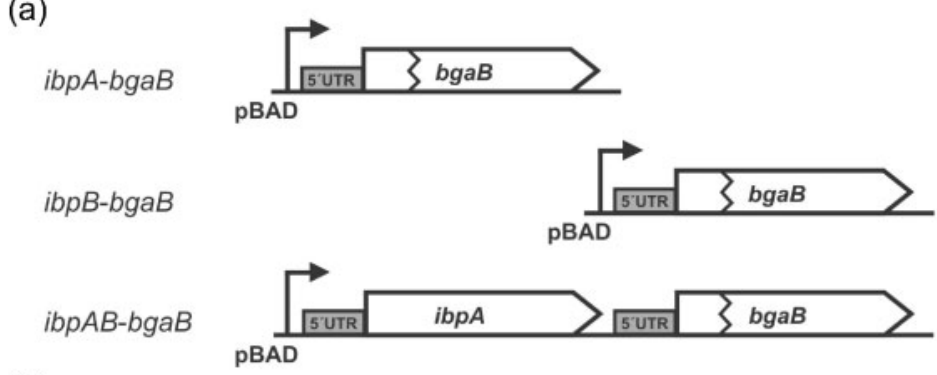

(b)

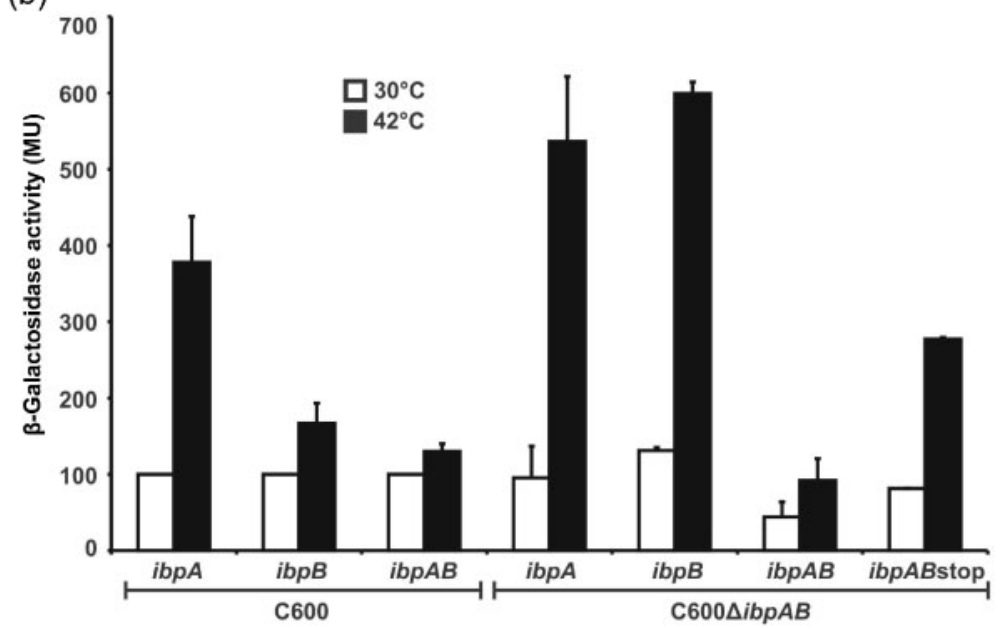

Fig. 6. Expression of ibpB in vivo. (a) Schematic view of the constructed $i b p-b g a B$ fusions. (b) Expression of translational ibpA, $i b p B$ and ibpAB fusions in E. coli $\mathrm{C} 600$ and the isogenic $\triangle i b p A B$ strain. After transcription induction with $0.01 \%$ L-arabinose, cells were heat-shocked for $30 \mathrm{~min}$ at $42{ }^{\circ} \mathrm{C}$ before $\beta$ galactosidase activity was measured. Activities are shown in Miller units (MU). Cells were grown at $30{ }^{\circ} \mathrm{C}$ to exponential phase.

contrast to the in vitro results, which showed temperaturedependent melting of, and ribosome binding to, the $i b p B$ RNA, the in vivo data argue against the temperatureregulated translation of $i b p B$.

Measurements of the same fusions in an E. coli C600 $\triangle i b p A B$ strain suggested a solution for this apparent puzzle. In the absence of any IbpA and IbpB protein, the $i b p B$ fusion showed heat induction like the $i b p A$ fusion (Fig. 6b) (Waldminghaus et al., 2009). Interestingly, expression was reduced in the $i b p A B$ fusion, which is able to produce IbpA from the reporter plasmid. The possible influence of the IbpA protein on $i b p B$ expression was determined by testing the introduction of a nonsense mutation at the beginning of the coding sequence of $i b p A$ in the $i b p A B$ fusion so that no IbpA protein could be synthesized from this plasmid. The temperature response of this fusion in the $\triangle i b p A B$ background was restored, suggesting that IbpA plays a role in controlling $i b p B$ expression.

\section{DISCUSSION}

Regulation of the heat-shock response in E. coli is complex and involves several mechanisms, mostly controlling the cellular level of the key regulator $\sigma^{32}$ in response to the physiological need (Guisbert et al., 2008). Here, we describe novel mechanisms that control expression of the $i b p A B$ operon at regulatory levels downstream of $\sigma^{32}$ mediated transcriptional control (Fig. 7).

\section{Transcriptional regulation and RNA processing}

Transcription of the $i b p A B$ operon has been reported to depend on the alternative sigma factor $\sigma^{32}$ (Allen et al., 1992). In certain nutrient-poor media, the distal $i b p B$ gene is transcribed from a $\sigma^{54}$-dependent promoter (KuczyńskaWisńik et al., 2001). However, this does not play a role under the conditions used in the present study because corresponding $5^{\prime}$ ends were not found by $5^{\prime}$ RACE experiments. The $\sigma^{32}$ promoter upstream of $i b p A$ is responsible for the massive, several hundred-fold induction of the $i b p A B$ operon after heat shock (Rasouly et al., 2009; Wade et al., 2006). The requirement for the heat-shock sigma factor was recapitulated in our experiments. Further, we discovered several RNA processing events that might result in differential expression of $i b p A$ and $i b p B$. Cleavage of the bicistronic $i b p A B$ transcript results in monocistronic $i b p A$ and $i b p B$ transcripts, the latter of which is further processed into short $3^{\prime}$ ends. The $5^{\prime}$ end of the monocistronic $i b p B$ transcript was mapped within the stop codon of $i b p A$. There are no apparent promoter sequences upstream of this site. Instead, the sequence around the mapped $5^{\prime}$ end (A ${ }^{\downarrow}$ AUUC) closely resembles the consensus sequence of an RNase E cleavage site RAUUW ( $R=A / U ; W=A / U)$, in which the cleavage usually occurs in the central AUU sequence (Ehretsmann et al., 1992). The g55/agt RNA from the T4 phage was demonstrated to be cleaved by RNase E in E. coli at exactly the same nucleotide sequence (A ${ }^{\downarrow}$ AUUC) as in the $i b p A B$ transcript (Loayza et al., 1991). Fully 


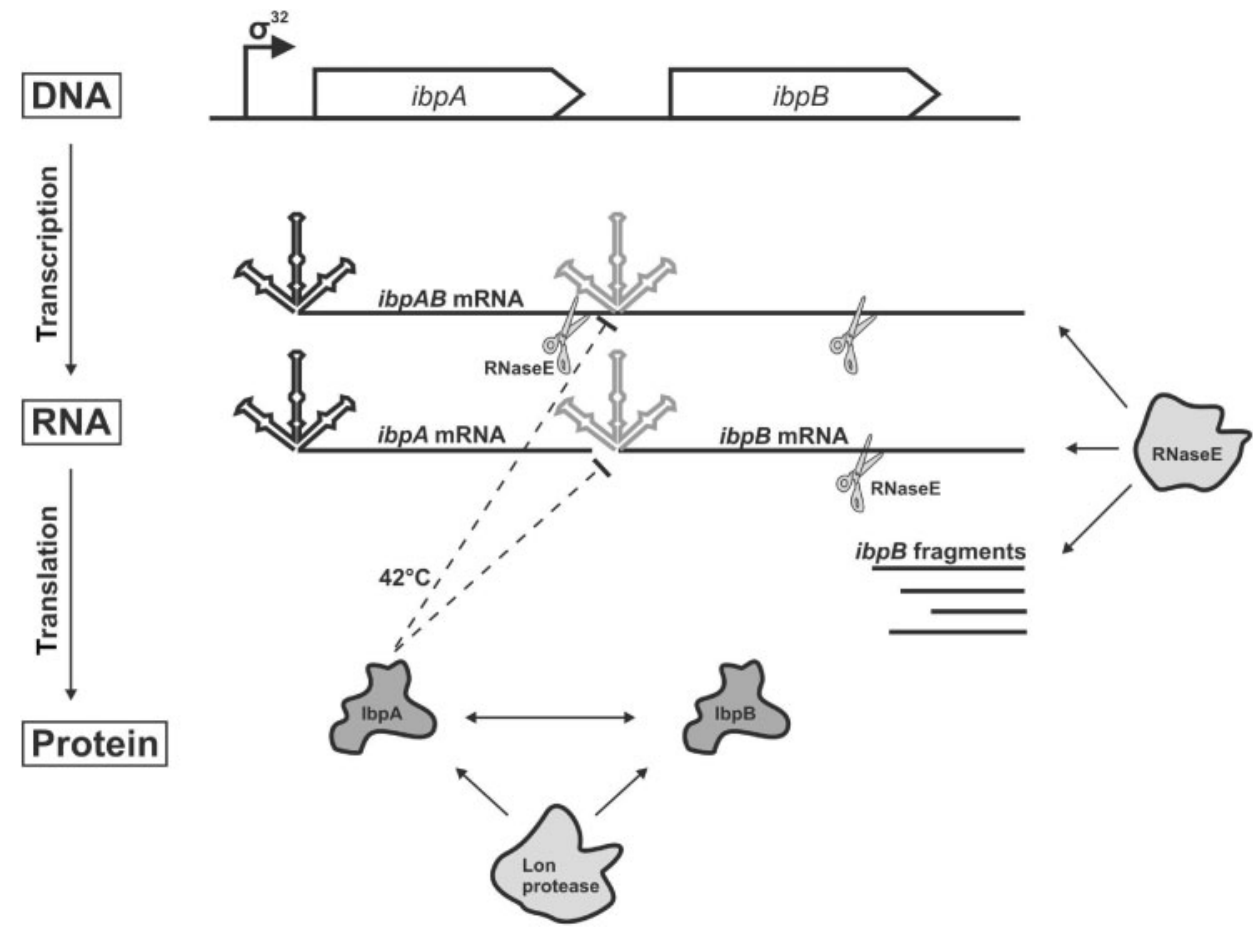

Fig. 7. Mechanisms involved in regulation of the $E$. coli ibpAB operon. See text for details.

consistent with the putative RNase E cleavage site, the $i b p B$ transcript was only detectable in the WT strain, whereas it did not appear in the temperature-sensitive RNase E mutant after heat inactivation of the enzyme.

Subsequent decay of the $i b p B$ RNA in the wild-type strain led to the transient accumulation of short degradation products containing the $3^{\prime}$ end of $i b p B$. The $5^{\prime}$ fragment was not detected, suggesting that it is rapidly degraded. In contrast to the well-defined initial cut in the $i b p A B$ transcript, the $i b p B$ fragments carry diverse $5^{\prime}$ ends. RNase E-dependent cleavage is known to be the ratelimiting step in mRNA degradation. It processes polyribosomal mRNA by cleaving in the translation-initiation region or in the intercistronic regions of polycistronic messages. The mRNA fragments generated are further cleaved at RNase E-sensitive sites located downstream (Carpousis, 2007; Jain, 2002). Several of the mapped 5' ends within the $i b p B$ mRNA are characterized by AU-rich sequences suggesting that RNase $\mathrm{E}$ is also responsible for this process.

\section{Translational and post-translational regulation}

Transcriptional induction of the $i b p A B$ operon and mRNA processing are complemented by further control mechanisms (Fig. 7). Translation of the ibpA gene is temperaturecontrolled by an RNA thermometer (Waldminghaus et al., 2009). The 5' UTR of the $i b p B$ gene also exhibits characteristics of a ROSE-like element (Narberhaus et al.,
2006). Toeprinting experiments indeed showed heatdependent binding of the $30 \mathrm{~S}$ ribosomal subunit to the $i b p B$ SD sequence in the monocistronic as well as in the bicistronic context. Structure-probing experiments suggested an opening of the RNA structure in hairpin IV, which harbours the $i b p B$ SD sequence. These in vitro results demonstrated that the structural properties of the $i b p B 5^{\prime}$ UTR allow thermoregulation of $i b p B$ translation. However, the temperature response in vitro was not reflected by translational fusions in vivo. Heat induction of an $i b p B-$ $\operatorname{bgaB}$ fusion was only detected when no IbpA protein was present in the cells. The two homologous small heat-shock genes $i b p A$ and $i b p B$ are believed to originate from a duplication event and were initially discovered as inclusion-body-binding proteins during the production of heterologous proteins in E. coli (Allen et al., 1992; Vaillancourt, 2003). In other studies it was shown that IbpA and IbpB levels increase almost 10-fold during overexpression of recombinant proteins while other heatshock proteins like DnaK and GroEL increase only 2-fold (Han et al., 2004). This suggests that IbpA and IbpB play an important role during recombinant protein production. Nevertheless, their cooperation and exact function in vivo are still not fully understood (Han et al., 2004; Matuszewska et al., 2008). The pool of substrates interacting with IbpA is much larger than that of IbpB (Butland et al., 2005). The presence of IbpA alone during substrate denaturation did not increase the efficiency of reactivation but rather inhibited this process. IbpA-mediated recruitment of IbpB reversed this inhibitory effect (Ratajczak et al., 
2009). Although IbpA and IbpB seem to have distinct activities, they depend on an intricate interplay between the two proteins.

For reasons not yet fully understood, IbpA accumulation is stronger than $\mathrm{IbpB}$ accumulation during ibpAB overexpression and in cells exposed to copper (Lethanh et al., 2005; Matuszewska et al., 2008). Our results suggest two possible reasons for differential expression of $i b p A$ and $i b p B$ (Fig. 7). First, processing of the $i b p A B$ transcript between $i b p A$ and $i b p B$ and subsequent cleavage within $i b p B$ might result in preferential accumulation of $i b p A$ transcripts in the cell. In addition, regulation of $i b p B$ expression by IbpA might constitute a second mechanism involved in reducing $i b p B$ expression. At present, we can only speculate on the putative mechanism of IbpA-mediated control. It is conceivable that IbpA interacts with the $i b p B$ mRNA to prevent translation and/or stimulate ribonucleolytic decay. In plants, small heatshock proteins are associated with mRNAs in heat-shock granules (Nover et al., 1989). Other reports have shown that small heat-shock proteins are able to interact with singlestranded and double-stranded DNA (Singh et al., 1998). Owing to its polydispersity and its tendency to precipitate, purification of IbpA for biochemical characterization is notoriously difficult (Shearstone \& Baneyx, 1999). Hence, all our attempts to demonstrate a direct interaction between the $i b p B 5^{\prime}$ UTR and IbpA failed. The recently discovered degradation of IbpA and IbpB by the Lon protease provides another explanation for differing cellular levels of the two proteins (Bissonnette et al., 2010). Proteolysis of IbpB was 15 -fold faster than IbpA degradation. Interestingly, decay of IbpA was accelerated 7-fold in the presence of IbpB. Taking these findings together with our results, it is tempting to speculate an antagonistic mechanism, in which the IbpA protein represses its own degradation by inhibiting the translation of $i b p B$. It is going to be a challenging task to obtain deeper mechanistic insights into the control of the $i b p A B$ operon.

\section{ACKNOWLEDGEMENTS}

We thank Birgit Klinkert for the generous gift of 30 S ribosome preparations, Ursula Aschke-Sonnenborn for technical assistance, and Gabriele Klug (University of Giessen) for sending RNase mutant strains. We are grateful to the German Research Foundation (DFG, SPP 1258) for financial support.

\section{REFERENCES}

Allen, S. P., Polazzi, J. O., Gierse, J. K. \& Easton, A. M. (1992). Two novel heat shock genes encoding proteins produced in response to heterologous protein expression in Escherichia coli. J Bacteriol 174, 6938-6947.

Bissonnette, S. A., Rivera-Rivera, I., Sauer, R. T. \& Baker, T. A. (2010). The IbpA and IbpB small heat-shock proteins are substrates of the AAA + Lon protease. Mol Microbiol 75, 1539-1549.

Brantl, S. \& Wagner, E. G. (1994). Antisense RNA-mediated transcriptional attenuation occurs faster than stable antisense/target
RNA pairing: an in vitro study of plasmid pIP501. EMBO J 13, 35993607.

Butland, G., Peregrin-Alvarez, J. M., Li, J., Yang, W., Yang, X., Canadien, V., Starostine, A., Richards, D. \& other authors (2005). Interaction network containing conserved and essential protein complexes in Escherichia coli. Nature 433, 531-537.

Campbell, E. A., Westblade, L. F. \& Darst, S. A. (2008). Regulation of bacterial RNA polymerase $\sigma$ factor activity: a structural perspective. Curr Opin Microbiol 11, 121-127.

Carpousis, A. J. (2007). The RNA degradosome of Escherichia coli: an mRNA-degrading machine assembled on RNase E. Annu Rev Microbiol 61, 71-87.

Chuang, S. E., Burland, V., Plunkett, G., III, Daniels, D. L. \& Blattner, F. R. (1993). Sequence analysis of four new heat-shock genes constituting the hslTS/ibpAB and hslVU operons in Escherichia coli. Gene 134, 1-6.

Ehretsmann, C. P., Carpousis, A. J. \& Krisch, H. M. (1992). Specificity of Escherichia coli endoribonuclease RNase $\mathrm{E}$ : in vivo and in vitro analysis of mutants in a bacteriophage T4 mRNA processing site. Genes Dev 6, 149-159.

Goldblum, K. \& Apririon, D. (1981). Inactivation of the ribonucleic acid-processing enzyme ribonuclease E blocks cell division. J Bacteriol 146, 128-132.

Gross, C. A., Chan, C., Dombroski, A., Gruber, T., Sharp, M., Tupy, J. \& Young, B. (1998). The functional and regulatory roles of sigma factors in transcription. Cold Spring Harb Symp Quant Biol 63, 141155.

Guisbert, E., Yura, T., Rhodius, V. A. \& Gross, C. A. (2008). Convergence of molecular, modeling, and systems approaches for an understanding of the Escherichia coli heat shock response. Microbiol Mol Biol Rev 72, 545-554.

Han, M. J., Park, S. J., Park, T. J. \& Lee, S. Y. (2004). Roles and applications of small heat shock proteins in the production of recombinant proteins in Escherichia coli. Biotechnol Bioeng 88, 426436.

Hartz, D., McPheeters, D. S., Traut, R. \& Gold, L. (1988). Extension inhibition analysis of translation initiation complexes. Methods Enzymol 164, 419-425.

Hengge-Aronis, R. (2002). Signal transduction and regulatory mechanisms involved in control of the $\sigma^{\mathrm{S}}$ (RpoS) subunit of RNA polymerase. Microbiol Mol Biol Rev 66, 373-395.

Jain, C. (2002). Degradation of mRNA in Escherichia coli. IUBMB Life 54, 315-321.

Kitagawa, M., Matsumura, Y. \& Tsuchido, T. (2000). Small heat shock proteins, IbpA and IbpB, are involved in resistances to heat and superoxide stresses in Escherichia coli. FEMS Microbiol Lett 184, 165171.

Kitagawa, M., Miyakawa, M., Matsumura, Y. \& Tsuchido, T. (2002). Escherichia coli small heat shock proteins, IbpA and IbpB, protect enzymes from inactivation by heat and oxidants. Eur J Biochem 269, 2907-2917.

Klinkert, B. \& Narberhaus, F. (2009). Microbial thermosensors. Cell Mol Life Sci 66, 2661-2676.

Kuczyńska-Wisńik, D., Laskowska, E. \& Taylor, A. (2001). Transcription of the $i b p B$ heat-shock gene is under control of $\sigma 32$ and $\sigma^{54}$-promoters, a third regulon of heat-shock response. Biochem Biophys Res Commun 284, 57-64.

Laskowska, E., Wawrzynow, A. \& Taylor, A. (1996). IbpA and IbpB, the new heat-shock proteins, bind to endogenous Escherichia coli proteins aggregated intracellularly by heat shock. Biochimie 78, 117122. 
Lethanh, H., Neubauer, P. \& Hoffmann, F. (2005). The small heatshock proteins IbpA and IbpB reduce the stress load of recombinant Escherichia coli and delay degradation of inclusion bodies. Microb Cell Fact 4, 6.

Loayza, D., Carpousis, A. J. \& Krisch, H. M. (1991). Gene 32 transcription and mRNA processing in T4-related bacteriophages. Mol Microbiol 5, 715-725.

Matuszewska, M., Kuczyńska-Wisńik, D., Laskowska, E. \& Liberek, K. (2005). The small heat shock protein IbpA of Escherichia coli cooperates with $\mathrm{IbpB}$ in stabilization of thermally aggregated proteins in a disaggregation competent state. J Biol Chem 280, 12292-12298.

Matuszewska, E., Kwiatkowska, J., Kuczyńska-Wisńik, D. \& Laskowska, E. (2008). Escherichia coli heat-shock proteins IbpA/B are involved in resistance to oxidative stress induced by copper. Microbiology 154, 1739-1747.

Miller, J. H. (1972). Experiments in Molecular Genetics. Cold Spring Harbor, NY: Cold Spring Harbor Laboratory.

Narberhaus, F. (2010). Translational control of bacterial heat shock and virulence genes by temperature-sensing mRNAs. RNA Biol 7, 8489.

Narberhaus, F. \& Vogel, J. (2009). Regulatory RNAs in prokaryotes: here, there and everywhere. Mol Microbiol 74, 261-269.

Narberhaus, F., Waldminghaus, T. \& Chowdhury, S. (2006). RNA thermometers. FEMS Microbiol Rev 30, 3-16.

Newbury, S. F., Smith, N. H. \& Higgins, C. F. (1987). Differential mRNA stability controls relative gene expression within a polycistronic operon. Cell 51, 1131-1143.

Nonaka, G., Blankschien, M., Herman, C., Gross, C. A. \& Rhodius, V. A. (2006). Regulon and promoter analysis of the E. coli heat-shock factor, $\sigma^{32}$, reveals a multifaceted cellular response to heat stress. Genes Dev 20, 1776-1789.

Norrander, J., Kempe, T. \& Messing, J. (1983). Construction of improved M13-vectors using oligodeoxynucleotide-directed mutagenesis. Gene 26, 101-106.

Nover, L., Scharf, K. D. \& Neumann, D. (1989). Cytoplasmic heat shock granules are formed from precursor particles and are associated with a specific set of mRNAs. Mol Cell Biol 9, 1298-1308.

Pridmore, R. D. (1987). New and versatile cloning vectors with kanamycin-resistance marker. Gene 56, 309-312.

Rasouly, A., Schonbrun, M., Shenhar, Y. \& Ron, E. Z. (2009). YbeY, a heat shock protein involved in translation in Escherichia coli. J Bacteriol 191, 2649-2655.

Ratajczak, E., Zietkiewicz, S. \& Liberek, K. (2009). Distinct activities of Escherichia coli small heat shock proteins IbpA and IbpB promote efficient protein disaggregation. J Mol Biol 386, 178-189.

Rauhut, R. \& Klug, G. (1999). mRNA degradation in bacteria. FEMS Microbiol Rev 23, 353-370.
Richmond, C. S., Glasner, J. D., Mau, R., Jin, H. \& Blattner, F. R. (1999). Genome-wide expression profiling in Escherichia coli K-12. Nucleic Acids Res 27, 3821-3835.

Sambrook, J., Fritsch, E. F. \& Maniatis, T. (1989). Molecular Cloning: a Laboratory Manual, 2nd edn. Cold Spring Harbor, NY: Cold Spring Harbor Laboratory.

Schumann, W. (2009). Temperature sensors of eubacteria. Adv Appl Microbiol 67, 213-256.

Shearstone, J. R. \& Baneyx, F. (1999). Biochemical characterization of the small heat shock protein IbpB from Escherichia coli. J Biol Chem 274, 9937-9945.

Singh, K., Groth-Vasselli, B. \& Farnsworth, P. N. (1998). Interaction of DNA with bovine lens alpha-crystallin: its functional implications. Int J Biol Macromol 22, 315-320.

Studier, F. W. (1975). Genetic mapping of a mutation that causes ribonucleases III deficiency in Escherichia coli. J Bacteriol 124, 307316.

Vaillancourt, P. E. (2003). E. coli Gene Expression Protocols. Totowa, NJ: Humana Press.

Veinger, L., Diamant, S., Buchner, J. \& Goloubinoff, P. (1998). The small heat-shock protein IbpB from Escherichia coli stabilizes stressdenatured proteins for subsequent refolding by a multichaperone network. J Biol Chem 273, 11032-11037.

Wade, J. T., Roa, D. C., Grainger, D. C., Hurd, D., Busby, S. J., Struhl, K. \& Nudler, E. (2006). Extensive functional overlap between sigma factors in Escherichia coli. Nat Struct Mol Biol 13, 806-814.

Waldminghaus, T., Fippinger, A., Alfsmann, J. \& Narberhaus, F. (2005). RNA thermometers are common in $\alpha$ - and $\gamma$-proteobacteria. Biol Chem 386, 1279-1286.

Waldminghaus, T., Gaubig, L. C. \& Narberhaus, F. (2007). Genomewide bioinformatic prediction and experimental evaluation of potential RNA thermometers. Mol Genet Genomics 278, 555-564.

Waldminghaus, T., Gaubig, L. C., Klinkert, B. \& Narberhaus, F. (2009). The Escherichia coli ibpA thermometer is comprised of stable and unstable structural elements. RNA Biol 6, 455-463.

Waters, L. S. \& Storz, G. (2009). Regulatory RNAs in bacteria. Cell 136, 615-628.

Willkomm, D. K., Minnerup, J., Huttenhofer, A. \& Hartmann, R. K. (2005). Experimental RNomics in Aquifex aeolicus: identification of small non-coding RNAs and the putative 6S RNA homolog. Nucleic Acids Res 33, 1949-1960.

Winkler, W. C. \& Breaker, R. R. (2005). Regulation of bacterial gene expression by riboswitches. Annu Rev Microbiol 59, 487-517.

Zuker, M. (2003). Mfold web server for nucleic acid folding and hybridization prediction. Nucleic Acids Res 31, 3406-3415.

Edited by: M. S. Paget 